\title{
LA TUTELA JUDICIAL EFECTIVA Y LA LIOUIDACIÓN CONCURSAL ENCOMENDADA AL CONSORCIO DE COMPENSACIÓN DE SEGUROS: LÍMITES CONSTITUCIONALES
}

\author{
POR \\ INMACULADA LÓPEZ-BARAJAS PEREA \\ Doctora en Derecho. Profesora de Derecho Procesal de la UNED
}

\section{INTRODUCCIÓN}

Desde 1984 en nuestro Derecho positivo han coexistido dos vías paralelas para resolver la crisis de las entidades aseguradoras: una de carácter general, decimonónica y probadamente ineficiente, atribuida al Poder Judicial; y otra específica del sector al que se refiere la crisis, de reciente cuño, y más eficaz desde un punto de vista económico, atribuida a la Administración.

Las características de cada cuerpo normativo determinaron que esta coexistencia haya sido meramente formal, ya que, de hecho, la quiebra y la suspensión de pagos de este tipo de entidades se convirtieron en un fenómeno absolutamente marginal, sustituido por la liquidación en sede administrativa. Desde que se creó la Comisión Liquidadora de Entidades Aseguradoras (CLEA) se han liquidado por esta vía más de 250 empresas de seguros frente a 6 concursos judiciales de entidades de esta naturaleza. Por su parte la Ley 44/2002 supri- 
mió el organismo autónomo CLEA y traspasó sus funciones al Consorcio de Compensación de Seguros.

La nueva Ley concursal 22/2003, que sin duda ha supuesto una de las más trascendentales reformas experimentadas por nuestro Ordenamiento en los últimos años, ha optado, sin embargo, por mantener las dos vías paralelas. Por un lado establece determinadas especialidades en el concurso judicial cuando afecte a una entidad aseguradora y; por otro, declara vigente el procedimiento administrativo como vía paralela al proceso común que regirá las insolvencias empresariales.

La heterogeneidad de los problemas que se suscitan, que son muchos, y de muy distinta naturaleza, hace necesario seleccionar tanto las cuestiones objeto de estudio, como la perspectiva desde la que se analizan. Nuestro análisis se centra, fundamentalmente, en el estudio de los aspectos que pueden afectar al encuadramiento constitucional de este sistema alternativo al concurso judicial.

\section{EFECTOS PROCESALES DE LA RESOLUCIÓN ADMINISTRATIVA DE LIQUIDACIÓN}

La resolución administrativa por la que se encomienda la liquidación de una entidad aseguradora al Consorcio de Compensación de Seguros, determina la apertura de un procedimiento, que produce dos importantes efectos procesales: de un lado, suspende todas las ejecuciones pendientes que hayan sido instadas por los acreedores contra la entidad aseguradora; y, de otro, impide, durante la tramitación del procedimiento, la apertura de procesos judiciales de ejecución universal.

Ambos efectos se configuran en el apartado $1 .^{\circ}$ del artículo 34 del Texto Refundido de la Ley de Ordenación y Supervisión de los Seguros Privados aprobado por Real Decreto Legislativo 6/2004, de 29 octubre, como particularidades propias de este procedimiento especial de liquidación administrativa y derivan de su carácter concursal, pues, como ha afirmado el Tribunal Constitucional ${ }^{1}$, al perseguir la misma finalidad que los procesos judiciales de ejecución universal (esto es, la liquidación de todos los créditos conjuntamente bajo el principio de la par conditio creditorum), es inevitable que se excluya su apertura y desarrollo simultáneos.

1 STC Pleno, sección. 4. a , de 21-1-1988, núm. 4/1988, Fecha BOE de 5-02-1988. 
Como es sabido, el concurso de acreedores, en su finalidad de liquidación, es un proceso de ejecución colectiva, lo que supone en palabras de SATTA ${ }^{2}$ "la transformación de los poderes procesales de los acreedores, los cuales no pueden perseguir al deudor con acciones individuales, dirigidas a la tutela de su interés".

La prohibición del ejercicio de acciones individuales ejecutivas, es decir, de todas aquéllas que tengan por objeto la expropiación del patrimonio del deudor, es coesencial a un proceso de esta naturaleza, pues lo que pretende es llevar a cabo una liquidación universal del patrimonio del deudor, aplicando todo su activo al pago de todo su pasivo bajo los principios de la pars conditio creditorum y de comunidad de pérdidas ${ }^{3}$. Esta liquidación universal devendría imposible si se permitiese la iniciación o continuación de las ejecuciones singulares contra el concursado 4 .

Pero, aunque la suspensión de las ejecuciones individuales pendientes contra el deudor constituya un medio imprescindible para que un proceso concursal cumpla la finalidad que le es propia, su aplicación a los nuevos procedimientos autónomos de ejecución general, dirigidos, exclusivamente, por un órgano de la Administración Pública, no integrado en el Poder Judicial, genera algunas dificultades. Un ejemplo paradigmático lo constituye el procedimiento dirigido por el Consorcio de Compensación de Seguros.

En el presente trabajo se va a analizar si la coincidencia de fines entre ambos tipos de procesos concursales debiera o no permitir una traslación automática de los medios empleados.

Aunque el proceso judicial de concurso de acreedores y el procedimiento administrativo de ejecución dirigido por el CCS sean procedimientos concursales que persigan la misma finalidad, las diferencias que existen entre ambos, centradas, fundamentalmente, en la naturaleza del órgano ejecutor (en el primer caso se atribuye a un órgano jurisdiccional y en el segundo a una Entidad administrativa), y en la na-

2 Vid. SATTA, S, Instituciones del derecho de quiebra, traducción española de Fontanarrosa, Buenos Aires, 1951, p. 196; Diritto Fallimentare, Tercera edición, Padova, Cedam, 1996, pp. 177 y ss.

3 Vid. DíEz-PICAZo Giménez (AAVV, Comentarios a la Ley de Enjuiciamiento Civil, Civitas, Madrid, 2001, p. 235; Ortells Ramos (AAVV, Proceso Civil Práctico, Gimeno SENDRA (Dir.), La Ley, 2002, p. 938).

4 Ramírez, J.A, La quiebra, Tomo II, Bosch, Barcelona, 1998, p. 1029; Cordón MoRENo, Suspensión de pagos y quiebra. Una visión jurisprudencial, Aranzadi, Pamplona, 1999, p. 166. 
turaleza de la resolución por la que se inician (judicial y administrativa respectivamente) son lo suficientemente relevantes como para ser tenidas en cuenta a la hora de establecer las garantías propias de cada procedimiento. Sea suficiente recordar de un lado, que la actividad administrativa se rige por unos principios diferentes a la actuación jurisdiccional y de otro, que el Juez goza de unas garantías especiales (como por ejemplo la independencia) de la que no disfrutan los demás funcionarios públicos 5 .

En virtud de lo dicho, la cuestión debe abordarse, no desde el punto de vista de la "legitimidad de los fines que persigue el proceso administrativo de ejecución" (que ha sido la perspectiva abordada por el TC en la sentencia 4/1988), sino de la legitimidad de los medios empleados; en concreto hay que determinar si, a la luz de nuestro Derecho Positivo, es posible que un acto administrativo pueda suspender la ejecución de una sentencia judicial.

La cuestión se centra en determinar bajo que condiciones la ejecución de lo juzgado, por ser expresión de la potestad jurisdiccional, debe atribuirse a órganos jurisdiccionales, sin que sea función pueda ser desarrollada por otros órganos de diferente naturaleza, ni siquiera con carácter previo y eficacia no definitiva ${ }^{6}$.

A lo anterior se suma la generalización que los procedimientos de liquidación administrativa han experimentado durante los últimos años. Con la promulgación de la Ley de Ordenación y Supervisión de los Seguros Privados de 1995 (LOSSP), el procedimiento de ejecución general administrativa dirigido por el CCS se convirtió en un instrumento ordinario de liquidación de las entidades aseguradoras, que ha dejado de fundarse en motivos de oportunidad, pues el legislador ha entendido que los problemas que resuelve no son meramente coyunturales sino estructurales del sector asegurador.

Además, la LOSSP sustituyó la enumeración detallada de causas que permitían encomendar la liquidación a la antigua Comisión Liqui-

5 Según Gimeno Sendra (Introducción al Derecho Procesal, Colex, Madrid, 2005, p. 25) la nota de la independencia distingue al Juez de cualquier otro funcionario público y a la actuación jurisdiccional de la administrativa.

6 Vid. Ortells Ramos, M., "Aproximación al concepto de potestad jurisdiccional en la Constitución española», Anuario de la Facultad de Derecho de la Universidad de Extremadura, Cáceres, 1984-1985 y «Exclusividad jurisdiccional para la restricción de derechos fundamentales y ámbitos vedados a la injerencia jurisdiccional», Medidas restrictivas de derechos fundamentales, Cuadernos de derecho Judicial, CGPJ, Madrid, 1996, p. 49. 
dadora de Entidades Aseguradoras (CLEA) incluyendo un supuesto indeterminado: cuando "por concurrir circunstancias que así lo aconsejen la Administración entienda que la liquidación debe encomendarse al Consorcion, causa que nuestro derecho positivo vigente recoge en el art. 14 del Estatuto Legal del Consorcio de Compensación de Seguros, aprobado por el Real Decreto Legislativo 7/2004, de 29 de octubre.

Estas circunstancias obligan a replantearse si la suspensión de acciones judiciales por una decisión administrativa entra o no en conflicto con el artículo 24 de la Constitución Española, que reconoce el derecho a la ejecución de las sentencias como parte integrante del derecho a la tutela judicial efectiva, o si infringe la competencia de ejecutar lo juzgado que el artículo 117.3 de la CE atribuye a los Juzgados y Tribunales.

\section{LA SUSPENSIÓN DE LAS EJECUCIONES PENDIENTES A LA LUZ DE LOS ARTÍCULOS 24.1 Y 117. 3 DE LA CONSTITUCIÓN ESPAÑOLA}

La suspensión de las acciones individuales quedó establecida para los supuestos de liquidación intervenida de un entidad aseguradora, en el artículo 32 de la antigua Ley de Ordenación del Seguro Privado 33/1984, de 22 de agosto, y de modo mas específico, para los supuestos de liquidación realizados por la CLEA, en el artículo 4.6 del RDL 10/1984, de 11 de julio, de creación de dicha entidad liquidadora ${ }^{7}$.

Se plantearon dudas sobre la constitucionalidad de estos artículos, basadas de un lado, en el posible menoscabo del ejercicio de la potestad jurisdiccional del artículo 117.3 de la CE, en tanto que priva temporalmente a los tribunales de su competencia para ejecutar sus propias sentencias $y$, de otro, en la posible vulneración del derecho a la tutela judicial efectiva del artículo 24.1 de la CE, en cuanto que suponía un obstáculo al derecho a la ejecución de las sentencias. Estas dudas fueron resueltas por el TC en la sentencia 4/1988, de 21 de enero (RTC 4\1988) en la cual se declaró la conformidad de los preceptos cuestionados con nuestra Ley Fundamental, basándose para ello en dos criterios: el de constitucionalidad de los fines que persigue este proceso es-

7 Vid. GARcía VilLAVERDE, «Institutos concursales y paraconcursales: el ámbito de una reforma", AAVV, Estudios sobre el Anteproyecto de Ley Concursal, Monográfico de la Revista de la Facultad de Derecho de la Universidad Complutense, n. ${ }^{\circ}$ 8, 1985, pp. 198-199. 
pecial de liquidación administrativa y el de proporcionalidad de los medios empleados, argumentos que, por razones de sistemática, serán objeto, mas delante, de una detenida consideración.

Tal y como se anunció, con la promulgación de la LOSSP de 1995 el procedimiento de ejecución general administrativa dirigido por el CCS se convirtió en un procedimiento ordinario de liquidación de las entidades aseguradoras. Su regulación se contempla, básicamente, en los artículos 31 a 37 del Texto Refundido de la mencionada ley, y concretamente el artículo 34 se ocupa de la suspensión de las ejecuciones pendientes estableciendo que, desde que se encomienda la liquidación al CCS y durante la tramitación por esta del procedimiento liquidatorio, quedan suspendidas todas las ejecuciones pendientes que hayan sido instadas por los acreedores contra la entidad aseguradora. La suspensión alcanza, no sólo a la ejecución de sentencias firmes, sino también a la ejecución de embargos preventivos, de las administraciones judiciales y demás medidas cautelares adoptadas por la autoridad judicial, del auto despachando ejecución en el procedimiento ejecutivo, a los procedimientos judiciales sumarios y ejecutivos extrajudiciales sobre bienes hipotecados o pignorados que se encuentren en el territorio español, así como la ejecución de las providencias administrativas de apremio ${ }^{8}$.

\subsection{Postura del Tribunal Constitucional (STC 4/1988)}

Con carácter previo conviene precisar que en el artículo 34.1 del Texto Refundido de la LOSSP el legislador ha querido dejar a salvo el derecho de acceso a los Tribunales para obtener una sentencia judicial, esto es, la tutela declarativa. Así se mantienen intactos (como ha declarado el Tribunal Constitucional (4/1988, FJ. 6), según veremos) los derechos de acceso al proceso, de obtención de un pronunciamiento de fondo y el eventual acceso a los recursos. No se impide, por tanto, que los acreedores de una entidad aseguradora puedan acudir a los Tribunales en lo que a la fase declarativa del proceso se refiere, es decir, para obtener la declaración de su derecho.

${ }^{8}$ El artículo 29.3 del Texto Refundido de la LOSSP también establece una regla general de suspensión de todas las ejecuciones individuales de los acreedores para los supuestos de liquidación intervenida por el Ministerio de Economía y Hacienda, pero con un alcance mas reducido que en la liquidación encomendada al Consorcio, pues se limita a la suspensión de la ejecución de las sentencias firmes durante un plazo máximo de un año desde la firmeza de la sentencia, transcurrido el cual quedará automáticamente alzada la suspensión. 
No ocurre lo mismo, sin embargo, con el ejercicio de acciones tendentes a obtener la ejecución de sentencias (dictadas antes o después de la encomienda de la liquidación al CCS) que quedarán en suspenso durante toda la tramitación del procedimiento liquidatorio.

La STC 4/1988, de 21 de enero, resolvió dos cuestiones de inconstitucionalidad acumuladas, planteadas respectivamente por la Magistratura de Trabajo num.13 de Madrid y por la Sala de lo Civil Audiencia Provincial de Valencia, contra los artículos 32 de la antigua Ley del Seguro de 33/1984, de 2 de agosto y contra el artículo 4.6 del Real Decreto Ley 10/1984, de 11 de julio, por el que se establecen medidas urgentes para el saneamiento del sector de seguros privados, por su supuesta contradicción con los artículos 24.1, 117.3 y 118 de la Constitución Española. Junto a las citadas normas constitucionales, que los órganos proponentes consideraban vulneradas, se añadían por la Magistratura de Trabajo las que garantizan la seguridad jurídica (art.9.3) y el derecho al trabajo y a una remuneración suficiente (art.35). Aquí sólo se expondrán los argumentos que utiliza el Tribunal Constitucional para abordar la posible contradicción con el derecho a la ejecución de las sentencias, que además constituye el núcleo central de la cuestión planteada. Estos argumentos se recogen en los fundamentos quinto, sexto y séptimo de la sentencia, y resumidamente declaran lo siguiente:

"...el de tutela judicial efectiva no es un derecho de libertad, sino un derecho prestacional, en sus diversas vertientes, lo que implica que es conformado por las normas legales que determinan su alcance y contenido concretos y establecen los requisitos y condiciones para su ejercicio... Por ello puede el legislador, mediante la definición apriorística, general y abstracta de los supuestos de hecho, aplazar la ejecución o supeditarla a la existencia o ausencia de determinadas condiciones, siempre que esta modulación de las reglas generales se haga en atención a finalidades lícitas y haya una proporcionalidad entre esto y la regulación legal..."

(pero se puede anticipar que junto a estos límites que menciona la sentencia analizada, también existen otros que deben ser tomados en cuenta).

Continúa su razonamiento el TC señalando que

"....aunque la medida consistente en la suspensión de las ejecuciones pendientes impide la efectividad inmediata del derecho a la ejecución de las sentencias, sin embargo, la medida es razonable, de un lado, porque con aquélla no se persigue una finalidad distinta, sino la misma a que se 
destina la fase de ejecución de los procesos: la satisfacción del derecho del acreedor con crédito reconocido judicialmente, y de otro, porque se persigue otra finalidad constitucionalmente atendible: la de liquidar todos los créditos conjuntamente, protegiendo así no sólo a quien por sentencia se le reconoció, sino también a otros asegurados o acreedores, en sus intereses económicos...".

Entiende el TC que las normas legales cuestionadas persiguen, así, la efectividad del principio de par conditio creditorum, en especial en favor de quienes no han contado con los medios e informaciones adecuados para acudir a los Tribunales con igual rapidez que otros y no se han visto beneficiados de la actuación de los liquidadores sociales hasta el momento.

De esta manera el TC declaraba que el procedimiento dirigido por la CLEA (hoy CCS)

"...constituye un procedimiento concursal que, incluso con garantía judicial posterior, asegura el reconocimiento y pago de los créditos según su naturaleza. Al perseguir la misma finalidad que los procesos universales, es inevitable que excluya su apertura y desarrollo simultáneos, pero deja abierta la posibilidad de acudir a ellos cuando el procedimiento administrativo fracasa..."

Junto a los fundamentos anteriores, el máximo garante de nuestra Constitución, concluía que

"... ha sido el Legislador, no la Administración, quien ha marcado la causa de suspensión de los procesos de ejecución que estuvieran pendientes ante los órganos judiciales, razón por la cual entiende este Tribunal que no se hace depender tal paralización ni su duración de decisiones o actos reglados o discrecionales de órganos administrativos..."

En virtud de todos estos fundamentos el TC declaró la conformidad de la legislación de seguros con los artículos 117.3, 118 y 24.1 de la CE.

De lo expuesto se deduce que el máximo garante de la Constitución, para declarar la constitucionalidad de la suspensión de ejecuciones pendientes que se produce en virtud de la iniciación del proceso especial de liquidación administrativa de una entidad aseguradora, se basa, fundamentalmente, en dos argumentos:

Primero, en el carácter del derecho a la tutela judicial efectiva como un derecho de configuración legal, que faculta al legislador a determinar el alcance y requisitos concretos para su ejercicio. 
Segundo, en la coincidencia de finalidades entre ambos procesos, el judicial y el administrativo, derivados de la naturaleza universal de ambos.

\subsection{Límites al poder de configuración legal del derecho a la tutela judicial efectiva}

En principio nada habría que objetar a la jurisprudencia del TC que, de forma clara y reiterada, manifiesta que el derecho a la tutela judicial efectiva, en sus diversas vertientes, no es un derecho absoluto, y por tanto no puede interpretarse como un derecho incondicional a la prestación jurisdiccional, sino que se trata de un derecho de prestación, de configuración legal, lo que implica el derecho a obtenerla siempre que se ejerza por las vías procesales legalmente previstas ${ }^{9}$.

El hecho de que la ejecución forzosa sea una manifestación del ejercicio de una potestad pública, supone que al Estado le corresponde libremente determinar cuáles son sus presupuestos, sus efectos y el modo en que debe ser realizada. Así, como ha señalado la doctrina ${ }^{10}$, la configuración legal de la tutela judicial ejecutiva se realiza detalladamente en los artículos 517 a 720 LEC 1/2000. Concretamente los artículos 565 a 569 de la LEC regulan la suspensión del proceso de ejecución con carácter general en cinco preceptos consecutivos, de entre los cuales el artículo 565, en su apartado primero contiene una regla general, que exige que la suspensión siempre ha de tener como fundamento una disposición legal que así lo exprese o el acuerdo de todas las partes personadas ${ }^{11}$. El soporte de la suspensión ha de ser, por tanto, legal o convencional ${ }^{12}$.

Ello no obstante, el legislador no puede establecer cualquier obstáculo al ejercicio del derecho a la tutela judicial efectiva, sino que su poder de configuración está sujeto a unos límites, que además deben de

9 Vid. Ortells Ramos, M., Derecho procesal civil, Aranzadi, Navarra, 2001, pp. 46 y ss.; De la Oliva Santos, Díez Picazo Giménez (Ig.) y Vegas TorRes, Derecho Procesal: Introducción, Centro de Estudios Ramón Areces, Madrid, 2001, pp. 420 y ss; AsENCIO Mellado, J.M., Introducción al Derecho Procesa, Tirant lo Blanch, Valencia, 2002, p. 188.

10 Ortells Ramos, M., Derecho procesal civil, Aranzadi, Navarra, 2001, p. 60.

11 Ortells Ramos, AAVV, Proceso Civil Práctico, Gimeno Sendra (Dir.), op. cit. p. 907.

12 Vid. Salinero RomÁn, AAVV, Comentarios a la nueva Ley de Enjuiciamiento Civil, Lorca Navarrete (dir); Guilarte Gutiérrez (Coor.), Valladolid, 2000, p. 2774. 
ser interpretados de forma restrictiva, cuando se trata de establecer obstáculos al ejercicio del mencionado derecho fundamental. Junto a los límites que expresamente se mencionan en la sentencia analizada (finalidad constitucional del procedimiento y proporcionalidad), también existen otros, que no se recogen en dicho pronunciamiento y que necesariamente deben ser tomados en cuenta. Estos límites son: de un lado, la competencia exclusiva del legislador para establecer limitaciones al derecho a la tutela judicial efectiva y, de otro, lado el respeto al contenido esencial del derecho.

\section{A) Límite competencial}

Ha declarado en numerosas ocasiones nuestro guardián del Texto Constitucional que "...nadie que no sea el legislador puede crear impedimentos o limitaciones al derecho a la tutela judicial, cuyo ejercicio "sólo por Ley" puede regularse ex art. 53.1 de la CE..." (STC 85/1999, de 30 de septiembre).

El hecho de que sea el legislador el único compete para configurar el derecho a la tutela judicial efectiva, supone que no es posible facultar o habilitar a otros "poderes" (como por ejemplo al Ejecutivo), de forma paralela y con los mismos límites que al legislador, para la configuración última del derecho en los distintos ámbitos de manifestación del mismo (STC 197/1988, de 24 de octubre, RTC 1988\197, F.3). Pues, en un Estado democrático de Derecho, del que la separación de poderes y el sometimiento de los jueces y la Administración al imperio de la Ley, constituye uno de sus pilares básicos, la creación de ésta corresponde al Poder Legislativo, de forma que su función tiene una legitimación democrática (STC 48/2001, de 26 de febrero).

Por ello, si el legislador dictara una ley que permitiese a la Administración determinar las causas, en virtud de las cuales puede suspenderse la ejecución de una sentencia firme, el poder de configuración del derecho a la tutela judicial efectiva se estaría traspasando a un órgano distinto del constitucionalmente establecido.

Esto es precisamente lo que parece ocurrir en la legislación de seguros privados. Como ha quedado expuesto mas arriba, el art. 34.1 de la LOSSP prevé la suspensión de todos los procedimientos de ejecución pendientes (incluidos los derivados de sentencia firme) una vez que se encomiende la liquidación de la entidad aseguradora al Consorcio. Al conectar esta previsión con la establecida en el 14 del Estatuto Legal del CCS, que recoge los supuestos en virtud de los cuales puede encomendarse la liquidación al CCS, se advierte que uno de dichos su- 
puestos consiste en que la Administración entienda que "concurran circunstancias que así lo aconsejan".

La expresión "concurren circunstancias que así lo aconsejan", es tan amplia que implica, en realidad, la atribución a la Administración de una facultad casi total para decidir la liquidación administrativa de la entidad aseguradora, ya que no existen unos límites objetivos en la apreciación de tales circunstancias, que pueden referirse a todos los aspectos posibles ${ }^{13}$. Por ello, si la Administración tiene una amplia facultad para decidir cuando procede la apertura del proceso de ejecución general administrativa y la apertura de este proceso produce como efecto inmediato la paralización de los procesos de ejecución pendientes, se puede afirmar que la paralización de las acciones ejecutivas judiciales de los acreedores se hace depender, aunque sea indirectamente, de la decisión de un órgano administrativo (lo cual se agrava si se tiene en cuenta, como mas adelante se verá, que se trata de una potestad discrecional). Ello implica que se está facultando a la Administración para la configuración última del derecho a la tutela judicial efectiva, lo cual choca frontalmente con el principio de división de poderes consagrado en nuestra Norma Suprema.

En efecto, como ha quedado expuesto, el legislador en el ejercicio de su poder de configuración del derecho a la tutela judicial efectiva está sujeto a los límites que la Constitución le impone, y uno de ellos es el competencial: sólo el Parlamento puede determinar las causas concretas que permiten una limitación al mencionado derecho como es la suspensión de la ejecución de una sentencia firme ${ }^{14}$.

\section{B) Respeto al contenido esencial del derecho}

Junto al límite competencial expuesto, la libertad del legislador en su poder de configuración del derecho a la tutela judicial efectiva, está sujeta a otro límite: debe respetar el contenido esencial del derecho (SSTC 99/1985 F.4, ATC 701/1988, F.1, STC 40/1988 F.2) ${ }^{15}$.

13 Cfr. Revilla González, J. A., "Liquidación administrativa de entidades aseguradoras: suspensión de la ejecución de sentencia de condena frente a la entidad y tutela judicial efectiva", en Estudios y Comentarios sobre la Ley de ordenación de los Seguros Privados, Madrid, 1997, p. 182.

14 Ríos SAlmerón, B., "La situación de los créditos laborales en la liquidación administrativa de entidades aseguradoras", REDT, 1988, n. ${ }^{\circ} 34$, pp. 202 y 203.

15 Torres del Moral, Principios de Derecho Constitucional Español, tomo I, Madrid, 2004. 
El análisis de este segundo límite tiene como obligado punto de partida el contenido y alcance del derecho a la tutela judicial efectiva recogido en el art. 24.1 CE. Como ha señalado de forma reiterada la jurisprudencia, este derecho cubre dos vertientes: la declaración de derechos y la ejecución de decisiones. Por ello, no agota su contenido en la exigencia de que el interesado tenga acceso a los Tribunales de Justicia, ni se limita a garantizar la obtención de una resolución de fondo fundada en derecho, sea o no favorable a la pretensión formulada, si concurren todos los requisitos procesales para ello, sino que además, exige que el fallo judicial se cumpla y que el recurrente sea repuesto en su derecho y compensado, si hubiere lugar a ello por el daño sufrido. Lo contrario sería convertir las decisiones judiciales y el reconocimiento de los derechos que ellas comportan a favor de una de las partes, en meras declaraciones de intenciones ${ }^{16}$.

La generalidad de la doctrina procesal se ha manifestado en el mismo sentido que la jurisprudencia constitucional, declarando que el cumplimiento de las sentencias y resoluciones judiciales firmes, forma parte del derecho a la tutela judicial efectiva, como contenido necesario del mismo, pues del proceso de ejecución y de su eficaz regulación procedimental, depende en gran medida la efectividad real de la tutela jurídica ${ }^{17}$.

La relevancia de este reconocimiento salta a la vista si se tiene en cuenta que, a partir de la integración del derecho a que el fallo se cumpla dentro del derecho a la tutela judicial efectiva, la ejecución se configura como un derecho fundamental con las consecuencias que esto supone. De esta manera, el obligado cumplimiento de lo acordado por los Jueces y Tribunales en el ejercicio de la potestad jurisdiccional se configura como una de las más importantes garantías para el funcionamiento y desarrollo del Estado de Derecho ${ }^{18}$.

La ejecución forzosa significa el ejercicio de una potestad pública, lo que supone que al Estado le corresponde determinar cuáles son sus presupuestos, sus efectos y el modo en que debe ser realizada. En uso

16 SSTC 55/2000; 206/1993, 207/1989; Vid. CANO MATA, A., El derecho a la tutela judicial efectiva en la doctrina del Tribunal Constitucional, Editoriales de Derecho Reunidas, Madrid, 1984, p. 13.

17 Cfr. Fernández-Ballesteros, M.A., La ejecución forzosa y las medidas cautelares, op. cit., p. 37; Asencio MelLADO, J.M., Derecho procesal civil. Parte segunda, Tirant lo Blanch, Valencia, 2001, p. 21.

18 Figueruelo Burrieza, El derecho a la tutela judicial efectiva, Tecnos, Madrid, 1990, p. 126. 
de esta facultad el legislador ha hecho de la ejecución una actividad estrictamente reglada, que implica que debe llevarse a cabo conforme a un plan previsto minuciosamente con anterioridad y recogido en preceptos de cumplimiento imperativo ${ }^{19}$.

Dado que la potestad de ejecutar las sentencias, no es una potestad discrecional, sino reglada, la norma general ha de ser que las resoluciones firmes habrán de ejecutarse siempre, salvo los justificados, excepcionales y tasados casos en que la ley autorice la suspensión de la ejecución (STC 15/1986) ${ }^{20}$. Por tanto, la ley puede contemplar, y de hecho prevé, supuestos de suspensión de la ejecución que, si bien no vulneran el derecho a la ejecución de las sentencias en sus propios términos, no dejan de constituir una excepción ${ }^{21}$. Al encontrarnos ante un supuesto de suspensión del ejercicio de un derecho fundamental, los casos en que procede han de estar taxativamente previstos y objetivamente justificados ${ }^{22}$ (SSTC 33/1987, de 12 de marzo, 205/1987, de 21 de diciembre). Queda proscrita cualquier suspensión de la ejecución de una sentencia firme que sea arbitraria e irrazonable y que no se funde en una causa taxativamente prevista.

\section{a) Taxatividad y discrecionalidad}

La potestad reconocida en los artículo 28 LOSSP y 14 del Estatuto legal del Consorcio, que atribuye al Ministerio de Economía y Hacienda la facultad de encomendar la liquidación de la aseguradora a dicho Consorcio "cuando concurran circunstancias que así lo aconsejen" pertenece al ámbito de la actividad administrativa discrecional.

Como no es nuestro propósito ahondar en el estudio de las potestades discrecionales de la Administración, basta señalar que, siguiendo a un importante sector de la doctrina administrativa ${ }^{23}$, la discrecionali-

19 Cfr. Fernández Ballesteros, M.A., La ejecución forzosa y las medidas cautelares, op. cit., p. 38.

20 Serrano Butragueño, I., "Ideas generales sobre la ejecución de sentencias civiles y penales" en Ejecución de sentencias civiles y penales, Instituto de Estudios Penales Marqués de Becaría, Madrid, 1994, p. 18.

21 García Pons, E., Ejecución de sentencia, PPU, Barcelona, 1995, p. 111.

22 Figueruelo Burrieza (El derecho a la tutela judicial efectiva, op. cit., p. 127) señala que "una decisión de inejecución habrá de apoyarse en la concurrencia de una causa prevista en una norma legal..." (STC 33/1987, STC151/1993).

${ }_{23}$ Vid. PARejo Alfonso, L., Administrar y juzgar: dos funciones constitucionales distintas y complementarias, Tecnos, Madrid, 1993; GARCíA DE ENTERRía, E, La lucha contra las inmunidades del poder, Madrid, 1979, p. 22 y ss; Democracia, jueces y 
dad no es un atributo del acto administrativo considerado como un todo, sino una cualidad de alguno de los elementos que componen el acto. Ello significa que dentro de una potestad calificada de discrecional, existen elementos reglados y discrecionales. Así, se considera que la existencia de la potestad, su extensión, la competencia para actuarla y el fin son siempre reglados. Por el contrario, pueden ser discrecionales el tiempo o momento del ejercicio de la potestad, la forma de ejercicio y el fondo del acto. Esto es lo que precisamente, en nuestra opinión, prohíbe el derecho a la tutela judicial efectiva, en donde no caben ámbitos de libre elección no fiscalizable por los tribunales.

A lo anterior se suma que todavía siguen existiendo importantes diferencias doctrinales y contradicciones en la jurisprudencia sobre el contenido y alcance del control judicial de las potestades discrecionales de la Administración ${ }^{24}$.

La Ley 29/1998, de 13 de julio reguladora de la Jurisdicción Contencioso Administrativa, no soluciona el problema, ya que no dispone un tratamiento específico para el control de la discrecionalidad administrativa. En el artículo 71.2, se limita a prohibir que los tribunales fijen el contenido discrecional de los actos anulados. Con esta técnica abstencionista, entiende la doctrina ${ }^{25}$, que el legislador parece seguir confiando en la jurisprudencia para configurar las modalidades y grado de intervención de la jurisdicción sobre la actividad administrativa discrecional.

Pero el estudio de la jurisprudencia en esta materia pone de manifiesto la falta de un denominador común y la existencia de importantes contradicciones, pues, en ocasiones, nuestro Tribunal Supremo limita su control a la mera comprobación de los elementos reglados y a la

control de la Administración, Madrid, 1997, p. 143-153; FERnÁNDEZ, T. R. , "Arbitrariedad y discrecionalidad", en Estudios sobre la Constitución Española, Homenaje al profesor Eduardo García de Enterría, Madrid, 1991, p. 2265; SÁInz Moreno, F, Conceptos jurídicos, interpretación y discrecionalidad administrativa, Madrid, 1976.

24 Vid. Parejo Alfonso, L, Administrar y Juzgar: dos funciones constitucionales distintas y complementarias, Tecnos, Madrid, 1993; FERNÁNDEZ, T.R., De la arbitrariedad de la Administración, Madrid, 1994; SÁNCHEZ MORóN, M, Discrecionalidad Administrativa y control judicial, Madrid, 1994 y "Siete tesis sobre el control de la discrecionalidad administrativa", en la obra, Eficacia, discrecionalidad y control judicial en el ámbito administrativo, Cuadernos de Derecho Judicial, Madrid, 1995.

${ }^{25}$ Cabañas García, J.C., El recurso contencioso administrativo, Madrid, 1999, p. 344; Vid. Gimeno Sendra, Moreno Catena, Garberí Llobregat, González Cuellar, Comentarios a la nueva Ley de la Jurisdicción Contencioso Administrativa, Madrid, 1999 , p. 522-523. 
averiguación de la posible desviación de poder por estimar que, en otro caso, estaría invadiendo un ámbito que es propio de la Administración. Pero este tipo de control mínimo se acepta, en unos casos, o se rechaza, en otros, para situaciones sustancialmente iguales, es decir, sin que existan diferencias claras entre unos supuestos y otros ${ }^{26}$. Entiende TOMAS TAMÓN FERNÁNDEZ ${ }^{27}$ que no existe una teoría válida del poder discrecional, porque todo concluye en un puro decisionismo, según el cual termina siendo discrecional aquello que el Juez se abstiene de criticar o corregir.

En concreto, en el ámbito que nos ocupa, que es el de las intervenciones y regulaciones de la economía, la jurisprudencia ha venido limitando habitualmente sus facultades de revisión a la simple comprobación de la regularidad externa o formal de las decisiones administrativas por entender que, de otro modo, invadiría competencias que privativamente correspondan a la Administración. La consolidación de esta práctica podría conducir al siguiente resultado: la decisión de la Administración de encomendar la liquidación de una entidad aseguradora al CCS, podría escapar del control jurisdiccional, cuando la mencionada decisión produce como efecto inmediato la paralización de la ejecución de todas las ejecuciones judiciales que estuvieren pendientes contra la entidad aseguradora.

Lo expuesto permite afirmar que la exigencia de taxatividad de las normas que establezcan limitaciones al derecho a la tutela judicial efectiva y, por ello, al derecho a la ejecución de las sentencias que forma parte de su contenido, se traduce, en nuestra opinión, en una prohibición de atribución a un órgano administrativo de potestades discrecionales de decisión que afecten al contenido del mencionado derecho. El hecho de que estemos hablando de una garantía constitucional exige que se evite la indeterminación, exigencia que no se cumple con las previsiones de la LOSSP. En ningún caso se puede justificar la vía de poner la eficacia por encima de los derechos fundamentales de la persona que son el fundamento del orden político y la paz social (art.101 CE). Eficacia y derecho a la tutela judicial efectiva no son principios del mismo valor.

26 FERnÁNDEZ, T. R., "Arbitrariedad y discrecionalidad", en Estudios sobre la Constitución Española, Homenaje al profesor Eduardo García de Enterría, Madrid, 1991, p. 2265. En este artículo el autor describe la evolución de la jurisprudencia sobre la potestad discrecional.

27 Fernández, T. R., "Arbitrariedad y discrecionalidad», op. cit., p. 2.293. 
b) Naturaleza jurisdiccional de ejecución

Dentro del límite representado por el respeto al contenido esencial del derecho, que debe de ser observado por el legislador en el poder de configuración del derecho a la tutela judicial efectiva, resulta pertinente hacer una reflexión sobre la naturaleza de la ejecución.

En consonancia con lo dispuesto en el art. 24.1 de la CE, el artículo 117.3 establece una regla de competencia que atribuye exclusivamente a los órganos jurisdiccionales la potestad de ejecución. Como ha afirmado GIMENO el art. 117.3 CE, al establecer que "en todo tipo de procesos el ejercicio de la potestad jurisdiccional juzgando y haciendo ejecutar lo juzgado corresponde exclusivamente a los Juzgados y Tribunales..." es suficientemente explícito y taxativo, y no deja al legislador puerta abierta alguna que permita sostener la naturaleza administrativa del proceso de ejecución ${ }^{28}$.

Pero con independencia de lo anterior, nuestro Derecho positivo deja claro que la ejecución tiene naturaleza jurisdiccional, ya que integra uno de los dos contenidos básicos de la potestad jurisdiccional ${ }^{29}$ (ex arts. 117.3 CE, 2.1 LOPJ, 55 y 919 LEC de 1881, y 61 y 545 LEC de 2000). La doctrina ${ }^{30}$ ha resaltado que esta naturaleza no proviene simplemente de que así lo establezca la ley, sino que la actividad ejecutiva es consustancial a la Jurisdicción o, si se prefiere, que la ejecución es actividad materialmente jurisdiccional. Y ello, porque está destinada a incidir de modo directo e inmediato en la esfera de los derechos subjetivos privados ${ }^{31}$, comporta una clara injerencia en la misma y, por tanto, son especialmente necesarios los principios de independencia, imparcialidad y sumisión a la ley, que caracterizan la función jurisdiccional.

28 Gimeno Sendra, Vicente, Constitución y proceso, Madrid, 1988, p. 165. A pesar de ello no ha faltado alguna opinión en contra dicha naturaleza jurisdiccional.

29 Gimeno Sendra, Cortés Domínguez, Moreno Catena, Derecho Procesal Civil. Parte General, op. cit, p. 447; Comentarios a la nueva Ley de Enjuiciamiento Civil, LoRCA NaVARRETE (Dir.), Valladolid, 2000, p. 2647.

30 Montero Aroca, J., Derecho Jurisdiccional II. Proceso Civil, Valencia, 2000, p. 502, con Gómez Colomer, J.L., Montón Redondo, A., Barona Vilar, S.; Fernández-BALLESTEROS, M.A., La Ejecución forzosa y las medidas cautelares en la nueva LEC, Madrid, 2001, p. 37.

31 Gómez de Liaño GonzÁlez, F., El Proceso Civil, Oviedo, 1992, p. 270, para quien la ejecución entraña graves peligros en orden a los derechos de la persona, debiendo revestirse necesariamente de las garantías que otorga la jurisdicción. Las desposesiones, lanzamientos, transferencias coactivas, constituyen expresiones típicas del poder jurisdiccional. 
La naturaleza jurisdiccional del proceso de ejecución es compatible con la existencia de procedimientos extrajudiciales de ejecución y con la posibilidad de someter a arbitraje las controversias derivadas de la ejecución de una resolución firme ${ }^{32}$. Pero, dicha compatibilidad deriva de que estos supuestos se mueven dentro del ámbito dispositivo, y se pueden reconducir a la autonomía de la voluntad de las partes.

Como no procede aquí entrar a enumerar las ejecuciones y apremios sobre el patrimonio que no se tramitan en sede jurisdiccional, basta poner como ejemplo, el procedimiento de realización extrajudicial de hipotecas, previsto por el artículo 129.2 de la Ley Hipotecaria, respecto al cual, el TS ha declarado su conformidad con el artículo 117 de la Constitución. Para ello se fundamenta en que el objeto de este procedimiento es ejecutar ante Notario un derecho de origen contractual, y no una resolución judicial ${ }^{33}$.

Ello no obstante, es necesario advertir que, de forma diferente, el mismo Tribunal Supremo, en sus Sentencias de 4 de mayo de 1998 y de 20 de abril de 1999, ha considerado que el denominado procedimiento extrajudicial para la realización de los bienes hipotecados es contrario a la exclusiva atribución a los órganos jurisdiccionales de la potestad de ejecutar lo juzgado reconocida por el art. 117.3 CE. Parte de la doctrina ${ }^{34}$ entiende incorrecta esta tesis toda vez que el notario no ejerce ninguna potestad de ejecución, ninguna coerción ni jurídica ni material sobre el patrimonio del deudor. La coerción que supondría el embargo es suplida por la constitución voluntaria de la hipoteca. Además al constituirse la hipoteca se designa la persona que, en su caso, otorgará la escritura en nombre del hipotecante. El nuevo art.129 de la Ley Hipotecaria, redactado por la LEC $1 / 2000$, exige que se pacte en escritura la venta extrajudicial conforme al art.1528 del Código Civil y que se designe persona que represente al deudor.

Con independencia de lo anterior podemos afirmar que, como también ha señalado nuestra jurisprudencia, el «monopolio jurisdiccional de las actividades de ejecución" se circunscribe a lo juzgado por los propios órganos jurisdiccionales (STS 8123\1995, de 23 de octubre, F.2). Lo anterior entra en conflicto con el procedimiento administrativo de liquidación de una entidad de seguros, cuya legislación especial prevé que, al margen de los procesos judiciales generales establecidos

32 FeRnÁNDEZ-BALlesteros, La ejecución forzosa y las medidas cautelares, op. cit., p. 37 , nota 35 .

33 En este sentido STS 7064/1995, de 16 de octubre, F. 5.

34 Ortells Ramos, Derecho Procesal Civil, op. cit., pp. 718 y 719. 
para los supuestos de insolvencia empresarial, la Administración, en uso de una facultad discrecional, decida la liquidación administrativa de la entidad, decisión que produce la paralización o suspensión de cualquier acción de los acreedores con finalidad ejecutiva.

La LEC, en el artículo 568, según su redacción tras la entrada en vigor de la nueva LC, prevé expresamente la suspensión de la ejecución, derivada de la existencia de un proceso concursal. Pero, como había señalado la doctrina ${ }^{35}$, el art. 568 no contempla un verdadero caso de suspensión. La característica fundamental del concurso, es que consume los procesos singulares de ejecución y concentra a todos los acreedores en un único proceso de ejecución, regido por la pars conditio creditorum. Tal es el fundamento de la aplicación al concurso de la institución procesal conocida con el nombre de la acumulación de autos en la LEC de 1881, que en la vigente LEC 1/2000 se denomina acumulación de procesos y que pretende, según el artículo 74 de la misma, que los juicios se sigan en un solo procedimiento y acaben por una sola sentencia.

Aunque esta misma realidad inspira el proceso administrativo dirigido por el CCS, existe una sustancial diferencia, basada precisamente en la diferente naturaleza de los órganos ejecutores, que determina que, en el proceso administrativo, no pueda existir acumulación de las ejecuciones pendientes, como ocurre en el proceso judicial de concurso. Pero, a pesar de ello, los derechos de los titulares de las resoluciones judiciales pueden ver realizados sus derechos dentro de la ejecución administrativa, toda vez que el art. 34 del Texto Refundido de la LOSSP dispone que una vez encomendada la liquidación al Consorcio, todos los acreedores quedan sujetos al procedimiento de liquidación por el mismo.

El Consorcio enajena los bienes de la entidad, clasifica las deudas de acuerdo con el orden de prelación previsto en el Derecho concursal común. Si la junta de acreedores aprueba el plan de liquidación, la minoría queda vinculada por lo que decida la mayoría sin que esta obligatoriedad se legitime, mediante la aprobación judicial del convenio, que si concurre en el concurso judicial. Una vez aprobado se procede al pago de los acreedores.

El propio TC, en la sentencia 4/1988, reconoce que se persigue la misma finalidad que la fase de ejecución de los procesos: la satisfacción del derecho del acreedor con crédito reconocido judicialmente.

35 Fernández-Ballesteros, M.A., La ejecución forzosa y las medidas cautelares, op. cit., p. 246. 
Esta previsión no es respetuosa con la naturaleza jurisdiccional de la ejecución y, por ello, se puede afirmar que el legislador al hacer uso de su poder de configuración del derecho a la tutela judicial efectiva, en lo que a la liquidación general de las entidades de seguros se refiere, con el artículo 34.1 de la LOSSP, no está respetando el contenido esencial del derecho.

\subsection{Límites a la ejecución administrativa por razones de oportunidad}

Una última y breve referencia debe hacerse sobre los motivos de oportunidad que, en ocasiones, se han esgrimido para fundamentar la existencia de los sistemas de ejecución encomendados a órganos de carácter administrativo. Dice FERNÁNDEZ LÓPEZ que, si la ejecución es materialmente jurisdiccional (ya que forma parte muy sustancial de la actividad necesaria para el otorgamiento de la tutela jurídica), sólo por razones de oportunidad, que considera criticables, pudiera encomendarse a órganos de carácter administrativo ${ }^{36}$. Pero, ni siquiera el criticable criterio basado en la oportunidad puede hoy utilizarse como justificación en el caso que nos ocupa, pues el procedimiento de ejecución general administrativa dirigido por el CCS, pasó a configurarse en la LOSSP de 1995, como un procedimiento ordinario de liquidación. Los problemas coyunturales del sector asegurador durante la década de los ochenta, que motivaron la aparición de este procedimiento especial de liquidación, se han convertido en problemas estructurales de dicho sector. Asistimos, actualmente, a una generalización de estos procedimientos de liquidación administrativa, que agrava la preocupación por las consecuencias de la paralización de la ejecución de las sentencias judiciales que los mismos producen. De hecho, la nueva Ley Concursal 22/2003, mantiene todas las especialidades que para las situaciones concursales se hallen establecidas en su legislación específica, sin perjuicio de reconocer que afecta a determinados aspectos del concurso.

Debe recordarse que el legislador constituyente español, dentro del amplio elenco de derechos fundamentales, contempló también como tal al derecho a la tutela judicial efectiva. Un derecho similar se había recogido en la Constitución italiana de 1947 y en la de la República Federal de Alemania de 1949, para impedir en el futuro los abusos y desviaciones del periodo totalitario y devolver a los ciudadanos su confianza en la Administración de justicia. Señala FigueRUELO ${ }^{37}$ que de

36 Fernández López, M. A., El Proceso de Ejecución, Barcelona, 1982, p. 28.

37 Figueruelo BurriezA, Á., El derecho a la tutela judicial efectiva, op. cit., p. 32 y 33. 


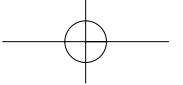

ahí procede el rechazo contra las distintas formas de protección jurídica realizadas en vía administrativa y contra los motivos de oportunidad adoptados para justificarlo.

Podemos concluir que el contenido de las potestades jurisdiccionales se extiende a la ejecución de lo juzgado, y por ello en nuestro sistema, la ejecución tiene naturaleza jurisdiccional ${ }^{38}$. La ejecución de la sentencia corresponde a los titulares de la potestad jurisdiccional de conformidad con las normas de competencia y procedimiento que las leyes establecen. El derecho a la tutela judicial, en cuanto es el poder jurídico que tienen los titulares de derechos e intereses legítimos de acudir a los órganos jurisdiccionales para reclamar la resolución de un conflicto, tiene su lugar propio de satisfacción en un proceso judicial (STC 197/1988, de 24 de octubre, RTC 1988\197, F.3). Por ello

"el derecho a la tutela judicial efectiva que reconoce y consagra el artículo 24 de la CE se refiere a una actividad prestacional del Estado, que es la prestación de actividad jurisdiccional por jueces y tribunales, es decir por los órganos jurisdiccionales del Estado, integrantes del Poder Judicial» (ATC 701/1988, F. 1).

\section{PROPUESTAS DE LEGE FERENDA}

A la hora de pronunciarse sobre las alternativas al vigente sistema previsto en la LOSSP debemos partir de lo ya expuesto. Así parece claro que un órgano administrativo no debe ejercer funciones jurisdiccionales, puesto que, como dice GIMENO ${ }^{39}$ aunque la Administración debe actuar con imparcialidad ex art. 103 de la CE, lo cierto es que, según nuestra Ley Fundamental, la independencia del funcionario no es suficiente para poder acometer actividades jurisdiccionales, puesto que el funcionario público no goza de inamovilidad judicial, ni de todo el conjunto de incapacidades, incompatibilidades y prohibiciones

38 Gimeno Sendra, Cortés Domínguez, Moreno Catena, Derecho Procesal Civil. Parte General, op. cit, p. 447.

39 Gimeno Sendra, Vicente, Constitución y proceso, op. cit., p. 58; Señala DE LA Oliva, (AAVV DiÉZ-PICAZo GIMÉnEZ (I.), VegAS TORRES, Derecho Procesal: Introducción, op. cit., pp. 24-26) que la posición de la Administración no es intrínsicamente descomprometida respecto de los asuntos de su incumbencia, como lo es, en cambio, la Jurisdicción, y por ello, cuando se habla de imparcialidad de la Administración, se hace referencia a una deseable cualidad subjetiva del comportamiento de los sujetos integrantes de los órganos administrativos, mas que de una característica intrínseca, que no existe, de la actividad de la Administración. 
que configuran el binomio independencia-responsabilidad en el que se desenvuelve la actividad del juez, estando en cualquier caso excluido del régimen de autogobierno, garantías todas ellas que conforme a los artículos 117,122 y 127 son inherentes a todo órgano jurisdiccional.

Asimismo, aunque la Administración debe servir con objetividad los intereses generales, actuando con sometimiento pleno a la Ley y al Derecho, la simultánea condición de Juez y parte que asume en el procedimiento administrativo no permite configurar su actuación como procesal, sino como autocompositiva ${ }^{40}$.

Por lo anterior el sujeto que debe ordenar la ejecución debe ser un órgano judicial, sin perjuicio de que en la práctica de la liquidación se recurra a un órgano administrativo. Esta solución no solo tiene el mérito de ser respetuosa con el principio de exclusividad de la jurisdicción en la fase de ejecución, sino que además la jurisdiccionalización de dicho procedimiento se realiza sin pérdida alguna de eficacia. Como es sabido, uno de los males que aquejaban a nuestros procesos de ejecución general clásicos, consiste en que debido a su carácter anacrónico no ofrecía respuestas para solucionar las crisis de las entidades financieras, por lo que, de trasplantar mecánicamente las prescripciones contenidas en la dispersa legislación concursal común en la materia, el remedio resultaría ser peor que la enfermedad. Aquí la legislación administrativa no tiene nada que aprender de la procesal, sino precisamente el fenómeno tiene que ser radicalmente inverso.

De hecho, en el Derecho comparado, la exclusión del juez en las liquidaciones administrativas de entidades aseguradoras no es tan radical como en el Derecho español. Así la «liquidazione coatta amministrativa" del Derecho Italiano prevé una mayor intervención del órgano jurisdiccional desde la iniciación del procedimiento. El artículo 195 de la "Legge fallimentare" establece que, cuando la empresa sujeta a liquidación forzosa administrativa, se encuentre en estado de insolvencia, corresponde al Tribunal donde la empresa tenga su sede, la declaración de tal estado, previa audiencia de la autoridad administrativa que tenga la vigilancia sobre la empresa. Esta sentencia debe comunicarse, en el plazo de tres días, a la autoridad competente para que disponga la liquidación y es la fecha de la resolución que ordena la liquidación, la que determina los efectos, que el estado de insolvencia produce sobre el patrimonio del deudor y sobre los acreedores, y en lo que aquí inte-

40 Gimeno SendRA, Introducción al Derecho Procesal, op. cit., p. 25. 
resa, la que produce la prohibición de la iniciación o continuación de la acciones individuales ejecutivas de los acreedores ${ }^{41}$.

Tal y como se expuso en otro trabajo anterior, a pesar de que la Corte Constitucional italiana declaró la constitucionalidad de la Liquidazione coatta amministrativa, la doctrina también ha manifestado su preocupación por la falta de presencia judicial ${ }^{42}$, reclamando un mayor control jurisdiccional.

\section{Title:}

"The effective judicial protection and the liquidation entrusted to the "Consorcio de Compensación de Seguros": Constitutional limits".

\section{Summary:}

1. Introduction. 2. Procedural effects of the administrative resolution of realization. 3. The suspension of pending executions in light of articles 24.1 and 117.3 of the CE: 3.1. Doctrine of the Constitutional Court (STC 4/1988). 3.2. Limits to the power of legal configuration of the right to an effective judicial protection: A. Competential limit B. Respect to the essential content of the right. 3.3. Limits to the administrative realization derived from reasons of opportunity. 4 . Some proposals de lege ferenda.

\section{Palabras clave:}

Tutela judicial efectiva, concurso de acreedores, par conditio creditorum, discrecionalidad administrativa, suspensión de ejecución de sentencias, potestades regladas.

${ }^{41}$ Del VeCCHO, Francesco, La liquidazione coatta amministrativa, Giuffrè, Milano, 1998, p. 31.

42 Vid. Uberto Tedeschi, G., Manuale di Diritto Fallimentare, cedam, Padova, 2001, p. 819; PROVINCIALI, Inconstitucionalitá della liquidazione coatta administrativa, en I/ Diritto Fallimentare, 1971, parte 1. ${ }^{\text {a }}$, pp. 738-739; PAJARDI, P., Manuale di Diritto Fallimentare. Milán, 1986, p. 738. 


\title{
Key words:
}

Effective judicial protection, insolvency, par condition creditorum, administrative discretion, suspension of execution of court resolutions, regulated powers.

\section{Resumen:}

Aunque en nuestro derecho positivo vigente existen dos vías para el caso de insolvencia de una entidad aseguradora, una judicial y otra administrativa, ésta última constituye el procedimiento común de liquidación. Se encomienda a un organismo público cuando concurra alguna de las causas que establece la Ley, dentro de las cuales se incluye un supuesto indeterminado consistente en que la Administración entienda que "concurren circunstancias que así lo aconsejen». Pero la iniciación del procedimiento administrativo afecta a los procesos judiciales de ejecución que estuvieren pendientes contra el patrimonio de la entidad aseguradora, produciendo su suspensión.

En el presente trabajo se analiza si la falta de una enumeración taxativa de causas supone un ámbito de discrecionalidad para el órgano administrativo supervisor que puede chocar con las garantías jurisdiccionales que se exigen por nuestra Ley Fundamental. Aunque la Administración debe actuar con imparcialidad ex art. 103 de la CE, lo cierto es que, según nuestra Ley Fundamental, la independencia del funcionario no es garantía suficiente para el desarrollo de actividades jurisdiccionales, puesto que éste no goza de inamovilidad judicial, ni de todo el conjunto de incapacidades, incompatibilidades y prohibiciones que configuran el binomio independencia-responsabilidad en el que se desenvuelve la actividad del Juez.

\begin{abstract}
:
Although our legal system in force provides two ways for the case of insolvency of an insurance entity, a judicial one and another administrative one, the latter constitutes the common procedure of liquidation. Liquidation is entrusted to a public entity in the cases provided for by the Law, within which it is included an undetermined case consisting in the fact that the Administration understands that «circumstances concur that makes the liquidation advisable». But the initiation of the administrative procedure has effects on the judicial processes of execution that are pending against the patrimony of the insurance entity, therefore producing its suspension.
\end{abstract}


This work analyses whether the lack of a closed enumeration of causes for liquidation entails a scope of discretion for the administrative supervisory agency that may clash with the jurisdictional guarantees established by our Fundamental Law. Although the Administration must act with impartiality ex- art. 103 of the Spanish Constitution, the fact is that, according to our Fundamental Law, the independence of the civil employee is not sufficient guarantee for the development of jurisdictional activities, since they do not enjoy judicial unremovability, nor of all the set of incapacities, incompatibilities and prohibitions that form the binomial independence-responsibility in which the activity of the Judge is developed. 